\title{
DENOMINAÇÃO DE ORIGEM E INDICAÇÃO GEOGRÁFICA DE PRODUTOS AGRÍCOLAS
}

\author{
Kazuo Leonardo Almeida Yokobatake ${ }^{1}$
}

Keny Samejima Mascarenhas Lopes ${ }^{2}$

Rafael Silvio Bonilha Pinheiro ${ }^{3}$

RESUMO: A certificação de produtos agropecuários traz 0 desenvolvimento socioeconômico e cultural para uma região específica. Produtos reconhecidos por sua denominação de origem e/ou indicação geográfica são mais valorizados no mercado pela tradicionalidade na elaboração. As denominações de origem surgiram nos tempos do Império Romano e Grego, com a finalidade de diferenciar produtos de características similares. Com essa forma de publicidade os produtos ganhavam fama e levavam o nome de sua região. Atualmente, existem regulamentos e leis que reconhecem ou não produtos para a certificação em alguns países, uma vez confirmada, produtores devem seguir as normas de produção específicas do produto. Desta maneira, o objetivo deste artigo de revisão foi identificar as vantagens da certificação de produtos regionais evidenciando a preservação e manutenção de áreas rurais específicas. A interação do homem com o meio-ambiente é de suma importância para conservar e manter o bioma para a produção, pois a tradição e ambiente é que mantêm as qualidades únicas desses produtos.

\footnotetext{
${ }^{1}$ Zootecnista, Faculdade de Engenharia/Unesp Campus de Ilha Solteira, Mestrando. kazuo.yokobatake@gmail.com.

${ }^{2}$ Zootecnista, Faculdade de Engenharia/Unesp Campus de llha Solteira, Mestrando. keny.samejima@gmail.com.

${ }^{3}$ Zootecnista, Faculdade de Engenharia/Unesp Campus de Ilha Solteira, Docente do Departamento de Biologia e Zootecnia. rafaelsbp@bio.feis.unesp.br.
} 
Palavras chave: Certificação. Ecossistemas. Preservação

\section{INTRODUÇÃO}

A produção, fabricação e distribuição de produtos do gênero alimentício ocupam uma posição de destaque na economia de uma comunidade, região ou país. Existe uma grande diversidade de produtos disponíveis aos consumidores, que cada vez mais procuram privilegiar em sua dieta produtos de qualidade, buscando alimentos certificados. Como esse mercado está crescendo, o desenvolvimento de produtos com características específicas pode tornar-se vantajoso para os produtores rurais, principalmente àqueles residentes em zonas desfavoráveis, devido ao clima, relevo, alagamentos, precipitação irregular e/ou estiagem prolongada, melhorando seus rendimentos e sua fixação no campo. Pensando neste conceito, produtos de áreas exclusas, podem ser reconhecidos por suas denominações de origem e indicações geográficas, levando consigo, garantia de qualidade e credibilidade aos produtores.

O Conselho das Comunidades Europeias (2006) define produtos de denominação de origem protegida (DOP) e/ ou indicação geográfica protegida (IGP), com o nome de uma região, local determinado ou em casos excepcionais um país para indicar um produto agrícola ou um gênero alimentício, cuja qualidade ou característica se devem, essencial ou exclusivamente, a um meio geográfico específico, incluindo fatores naturais. No Brasil, a Lei de Propriedade Industrial de 1996 considera a indicação geográfica (IG) a indicação de procedência (IP) e a denominação de origem (DO), dando ao Instituto Nacional da Propriedade Industrial (INPI) a competência para estabelecer as condições de registro das indicações geográficas; a indicação de procedência refere-se ao nome do local que se tornou conhecido por produzir, extrair ou fabricar determinado produto; a denominação de origem refere-se ao nome do local, que passou a designar produtos, cujas qualidades ou características podem ser atribuídas a sua origem geográfica. Neste sistema produtivo protecionista e tradicional, há a necessidade da criação de medidas defensivas ao ambiente, para que não haja alterações no produto final.

Assim de maneira sustentável, a atividade contribui para o desenvolvimento socioeconômico da região, pois agrega valor ao produto, e concomitantemente, mantêm e valorizam-se as características naturais do meio. Existe no mundo, uma variedade imensa 
de produtos agropecuários reconhecidos como DOP e/ou IG, principalmente na Europa, provindo de espaços de agricultura marginais e com solos menos férteis. As empresas agrícolas tradicionalmente familiar certificadas, têm papel crucial na manutenção e preservação de áreas desfavoráveis à produção em larga escala, contribuindo para a preservação da diversidade de paisagens e de ecossistemas de grande sensibilidade (TEIXEIRA, 2009).

O objetivo desta revisão de literatura foi conhecer e comentar sobre a importância dos produtos agropecuários que apresentam denominação de origem protegida e/ou indicação geográfica em diversas regiões do mundo.

\section{DESENVOLVIMENTO}

\subsection{Origem e regulamentação de produtos de Denominação de Origem Protegida e Indicação Geográfica}

Oliveira (2010) descreve as denominações de produtos específicos ocorridos inicialmente com os povos gregos e romanos, onde os produtos eram designados pelos nomes das terras onde eram produzidos, a fim de determinar a diferenciação entre produtos em termos de qualidade. Sendo que em 1756, Portugal foi primeiro país Europeu a instituir legalmente um sistema de proteção aos seus produtos, especificamente o Vinho do Porto, pelo Marquês de Pombal. Portanto, há tempos o nome do local de origem dos produtos é utilizado na distinção de similares e também como uma forma de publicidade, caracterizando uma ligação do parâmetro de qualidade com a região de origem do produto.

Ao longo dos anos, houve poucas mudanças sobre o conceito desses produtos, porém sabe-se que existem muitos produtos de DOP e/ou IG no mercado (PEREIRA, 2011). Produtos tradicionais que carregam sua marca de qualidade por décadas ou séculos. Lima et al. (2007), mencionaram a existência de 4900 indicações geográficas registradas na Europa, onde a França é redentora do selo de proteção mais antigo ou o Selo de Apelação de Origem Geográfica, criado para regulamentar e proteger o uso dos nomes geográficos que designam produtos alimentícios e agrícolas. Em 1992, o Conselho da União Européia criou o REGULAMENTO (CEE) № 2081/92 relativo à proteção das 
indicações geográficas e denominações de origem dos produtos agrícolas e dos gêneros alimentícios. Em 2006, o regulamento de 1992 foi revogado e substituído pelo REGULAMENTO (CE) № 510/2006, de mesmo nome, e por definição classifica os produtos certificados em:

Denominação de origem: o nome de uma região, de um local determinado ou, em casos excepcionais, de um país, que serve para designar um produto agrícola ou um gênero alimentício: originário dessa região, desse local determinado ou desse país; cuja qualidade ou características se devem essencial ou exclusivamente a um meio geográfico específico, incluindo os fatores naturais e humanos, e; cuja produção, transformação e elaboração ocorrem na área geográfica delimitada. Indicação geográfica: o nome de uma região, de um local determinado ou, em casos excepcionais, de um país, que serve para designar um produto agrícola ou um gênero alimentício: originário dessa região, desse local determinado ou desse país, e; que possui determinada qualidade, reputação ou outras características que podem ser atribuídas a essa origem geográfica, e; cuja produção e/ou transformação e/ou elaboração ocorrem na área geográfica delimitada. (REGULAMENTO (CE), 2006)

No Brasil, as indicações geográficas (IG) compreendem as indicações de procedência (IP) e/ou denominação de origem (DO) regulamentada pela Lei 9279/96 - Lei de Propriedade Industrial/96. As certificações de IG desperta interesse dos produtores nacionais, pois além de não ter validade é um fator decisivo na garantia da proteção, diferenciação e valorização do produto no mercado. Segundo a lei vigente todos os produtos certificados devem ser identificados (Figura 1). A proteção estender-se-á à representação gráfica ou figurativa da indicação geográfica, bem como à representação geográfica de país, cidade, região ou localidade de seu território cujo nome seja indicação geográfica (BRASIL, 1996). 


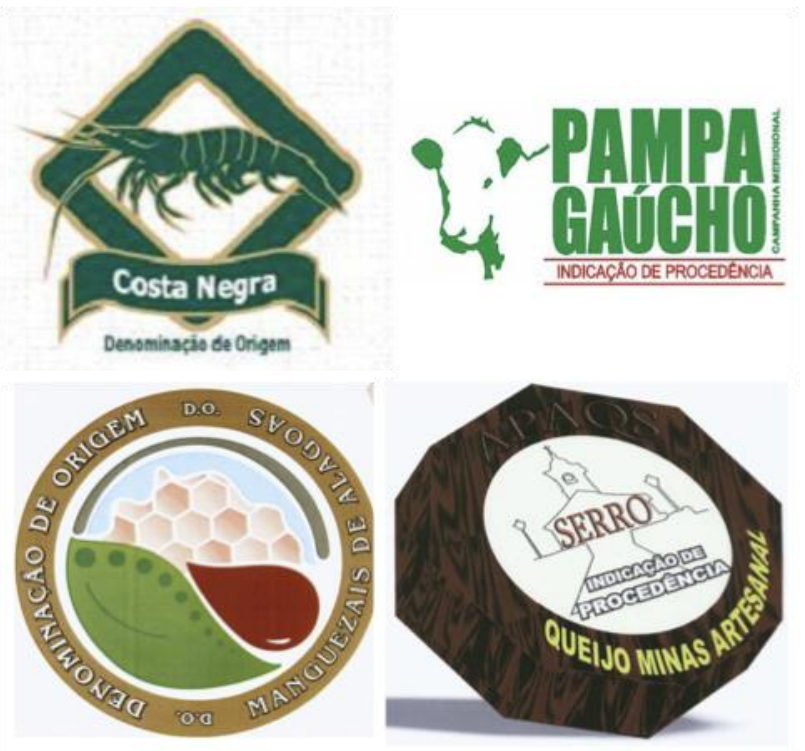

Figura 1 Representação figurativa de produtos brasileiros reconhecidos como DO e/ou IP. Fonte: INPI (2013).

Em estudos realizados com a população europeia, evidenciou-se que $37 \%$ dos consumidores reconhecem as certificações como garantia de qualidade, 56\% além de qualidade, também garantia de método de produção e 17\% tradição (KAKUTA, 2006). Foi destacado, que $43 \%$ dos consumidores europeus estão dispostos a pagar até $10 \%$ a mais por produtos com indicação geográfica reconhecida, e cerca de $11 \%$ pagariam um preço que pode variar entre $20 \%$ e $30 \%$ maior por produtos certificados. A discrepante diferença entre a Europa e outras regiões do mundo advém da tradicionalidade na elaboração. Apesar de parecer relativamente novo, o regulamento europeu, comtempla aos produtores de Estados-Membro da União Europeia (UE) que já haviam reconhecido seus produtos como DOP e IG, anteriormente a sua formação. O produtor brasileiro, recentemente, desperta o interesse sobre este sistema de certificação, como forma de valorizar seu produto, porém pensando não somente nos benefícios econômicos, mas também na preservação de tradições de elaboração/cultivo, cultura intelectual da região e biomas tão específicos de nosso país.

2.2 Produtos de Denominação de Origem e Indicações Geográficas e seus ambientes 
A lista de produtos agropecuários europeus certificados é vasta, por sua tradicionalidade em medidas protecionistas, alguns deles são descritos a seguir: Carne Barrosã, Mirandesa, Mertolenga, Chameca, de Vitelo Cruzado dos Lameiros de Barroso, Mel do Parque de Montesinho, de Barroso, dos Açoures, da Terra Quente, Lingüiça e Salpicão de Vinhais, Alheira de Mirandela, Cabrito de Barroso, Queijo Terrincho, Camembert, Roquefort, Serra da Estrela, Gorgonzola, Feta, Brie, Parmesão, de Cabra Transmontano, do Pico e Serpa, Presunto de Parma, Presunto Pata Negra, Borrego Terrincho, Mortadella Bologna, Salsicha de Lincolnshire. Na America Latina tem como produtos protegidos o café da Colômbia, o Pisco do Peru, a tequila e o café de Vera Cruz no México e em Cuba os charutos. No Continente Africano o óleo de oliva Argan e o abacaxi da Guiné. A Ásia especificamente na China o vinho amarelo de Shaoxing e o chá da Srilanka (SILVA, 2008; GUIMARÃES FILHO, 2011; ALMEIDA, 2004)

Em determinadas regiões do mundo a produção pecuária é dificultada por sua geografia, impossibilitando o cultivo de culturas tradicionais para a manutenção alimentar dos animais (TIBÉRIO e CRISTÓVÃO, 2001). Por esse motivo, os animais são criados com os alimentos (plantas nativas) disponíveis nestas zonas, que muitas vezes são de ocorrência única. Estes animais são considerados irreprodutíveis em outras áreas, denominando assim os produtos DOP, como os produtos de ovinos da Raça Churra Galega Bragançana e dos caprinos da Raça Serrana desenvolvidas em Portugal. Seus produtos de denominação de origem protegida são: cordeiro Bragançano; queijo de cabra Transmontano e cabrito Transmontano respectivamente. Os ovinos da raça Bragançano têm como zona de produção localidades montanhosas e pouco férteis, assim estão aptos a se alimentarem de dietas pobres a base de pastagens de tojos e giestas (OLIVEIRA, 2011).

No Brasil, o camarão Costa Negra, contemplado com a certificação DOP em 2011, tem o título de melhor e mais caro camarão do mundo segundo a Associação dos Carcinicultores da Costa Negra (ACCN, 2013). Produzido no Ceará, em área denominada Costa Negra (entre a foz do Rio Aracatimirim e a foz do Rio Guriú), está inserida na Microrregião do Vale do Acaraú, ambiente de águas escuras e ricas em nutrientes, que ajudam a transformar o solo costeiro na melhor área biológica para a produção do camarão (GIESBRECHT, 2011). 


\section{Then \\ Fórum Ambiental \\ da Alta Paulista}
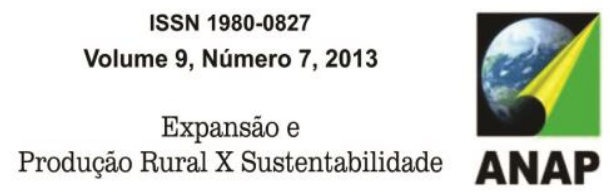

Nos exemplos de produtos já certificados acima, caracteriza-se o ambiente necessário para a produção específica de cada um. Entretanto a degradação desse meio pode trazer consequências inestimáveis aos produtores, como perda na qualidade do produto final, valor agregado e credibilidade no mercado consumidor. Diante do regulamento a que o produto está regido, deve-se haver o comprometimento do produtor em enfatizar a manutenção e preservação do ambiente, raças animais autóctones e variedades vegetais (RODRIGUES, 2003)

\subsection{Realidade brasileira sobre a certificação de produtos agrícolas}

Atualmente no Brasil, existem 16 produtos agropecuários certificados como Indicação de Procedência e 04 Denominações de Origem, totalizando 20 produtos genuinamente brasileiros segundo o INPI. Esses números ainda são inexpressivos, quando comparados com a quantidade de produtos certificados na Europa. Porém, há a possibilidade de se aumentar o número de produtos deste sistema fundamentando-se nas relações da produção animal com o bioma em que estão inseridos, em sistema de utilização mínima de insumos externos e evidenciando as tipicidades locais/regionais brasileiras (GUIMARÃES FILHO, 2011). A regulamentação de uma IG busca a confirmação histórica, cultural, mobilizando e identificando recursos territoriais e naturais para caracterizar sua especificidade, com o objetivo de valorizar o produto para 0 mercado, seja regional, nacional ou internacional. Para utilizar-se desse recurso como uma ferramenta de promoção de desenvolvimento sustentável, os projetos para reconhecimento de IG, deveriam assumir a preservação e manutenção da área delimitada de produção como finalidade principal (VELLOSO, 2008).

A diferenciação em qualidade, garantida pela certificação, de produtos tipicamente brasileiros ainda não reconhecidos como DO ou IG, poderia dar condições de competitividade no mercado, perante os produtos de comercialização em larga escala. Devido a alta diversidade cultural e natural do Brasil, muitos produtos típicos são elegíveis ao processo de avaliação do INPI. No nordeste, temos a carne de sol de Picuí e o queijo de manteiga do Seridó-PA/RN, o cordeiro de Tauá-CE, o cabrito do Sertão pernambucano do São Francisco, o queijo de leite de cabra de Cariri, o queijo coalho de Bodocó-PE, o mel de abelhas do Araripe-PE, a galinha caipira do semiárido piauiense, o mel de abelhas de Tucano, o cordeiro de Casa Nova-Remanso, o cabrito de Uauá, entre outros 
(GUIMARÃES FILHO 2005; GUIMARÃES FILHO, 2011). No centro-oeste, temos a carne de Curraleiro Kalunga da Microrregião Chapada dos Veadeiros em Goiás, raça bovina autóctone adaptada às condições adversas do Cerrado brasileiro (NEIVA et al., 2011). No norte, peixes ornamentais do Médio e Alto Rio Negro e no sul, o vinho Goethe e outros.

O reconhecimento desses produtos é importante para o enriquecimento socioeconômico das regiões citadas. Porém, somente a certificação não garante a inserção do produto no mercado (ALTMANN, 2005). Há a necessidade de políticas públicas ativas para consolidar o produto em sua região, para posteriormente buscar o mercado nacional e/ou internacional. Além disso, o sistema produtivo e o regulamento de produção devem ser conhecidos e respeitados pelos produtores, processadores e distribuidores, para não haver diferenciação de produtos de mesmo selo. Seguindo essas premissas, os resultados podem ser efetivamente impactantes na melhoria de utilização dos recursos naturais do solo e água, preservação de raças e espécies vegetais nativas. Além disso, permite a integralização do homem, da cultura e bioma em que está inserido (GUIMARÃES FILHO, 2006).

\section{CONSIDERAÇÕES FINAIS}

As certificações de produtos agropecuários valoriza o mesmo e também auxilia a fixação do homem no campo, assim como o desenvolvimento socioeconômico e cultural de regiões, viabiliza a sustentabilidade do sistema de produção e do meio ambiente desde que todas as partes envolvidas se integrem em um consenso comum. Como consequência, há também a manutenção e preservação de ecossistemas específicos em diversas regiões do mundo.

\section{REFERÊNCIAS}

ACCN. Associação dos Carcinicultores da Costa Negra. Disponível em: <http://www.accn.org.br/costa-negra>. Acesso em: 30 ago. 2013.

ALMEIDA, A.F.R. Indicações de proveniência, denominações de origem e indicações geográficas. In: Curso de Pós-Graduação em Propriedade Industrial, 5., 2004, Portugal, Anais... Portugal, $30 \mathrm{p}$. 
ALTMANN, R. Certificação de qualidade e origem e desenvolvimento rural. In: LAGES, Vinicius et al. (Org.). Valorização de produtos com diferencial de qualidade e identidade: indicações geográficas e certificações para competitividade nos negócios. Brasília: Sebrae, 2005. p.133-140.

BRASIL, Ministério da Justiça. Lei $n^{\circ}$, de 14 de maio de 1996. Regula direitos e obrigações relativos à propriedade industrial. Diário Oficial [da] República Federativa do Brasil, Brasília, DF, 15 mai. 1996.

CONSELHO DAS COMUNIDADES EUROPÉIAS. Regulamento (CE) n.510/2006, de 20 de Março de 2006, relativo à protecção das indicações geográficas e denominações de origem dos produtos agrícolas e dos géneros alimentícios. EUR-Lex: Jornal oficial n. L 93 de 31/03/2006 p.14.

CONSELHO DAS COMUNIDADES EUROPÉIAS. Regulamento (CEE) n.2081/92, de 14 de Julho de 1992, relativo à protecção das indicações geográficas e denominações de origem dos produtos agrícolas e dos géneros alimentícios. EUR-Lex: Jornal oficial $\mathrm{n}$. L 208 de 24/07/1992 p.01- 08.

GIESBRECHT, H. O. Indicações geográficas brasileiras. Brasília, DF: SEBRAE, INPI, 2011. $148 \mathrm{p}$.

GUIMARÃES FILHO, C. Certificação de indicação geográfica: Uma estratégia de inserção no mercado para produtos do Semiárido. Bahia Agrícola, v.9, n.1, p.42-49, 2011.

GUIMARÃES FILHO, C. Uma estratégia de inserção no mercado para a caprino e ovinocultura de base familiar do Semi-Árido. In: SEMINÁRIO NORDESTINO DE PECUÁRIA - PECNORDESTE, 9., 2005, Fortaleza. Anais... FAEC/CNA/SENAR/SEBRAE, 2005. 1 CD-ROM

GUIMARÃES FILHO, C.; SILVA, P. C. G. da. A pesquisa da Embrapa como base para a viabilização da agricultura familiar no Semi-Árido brasileiro: principais tecnologias e sistemas sustentáveis de produção desenvolvidos e em desenvolvimento pelo sistema Embrapa para a agricultura familiar no Semi-Árido. Petrolina: Embrapa Semi-Árido, 2006.14 p.

INPI. Instituto Nacional da Propriedade Industrial (Brasil). Disponível em: <http://www.inpi.gov.br>. Acesso em: 29 ago. 2013.

KAKUTA, S. M., SOUZA, A. L., SCHWANKE, F. H., GIESBRECTH, H. O. Indicações geográficas: guia derespostas. Porto Alegre: Sebrae/RS, 2006. 38p.

LIMA, F. D.; GIESBRECHT, H. O.; LIMA, S. U. Indicação geografica: Agregação de valor aos produtos Amazônicos. T\&C Amazonia, v.V, n.11, 2007.

NEIVA, A.C.G.R., SERENO, J.R.B., FIORAVANTI, M.C.S. Indicação geográfica na conservação e agregação de valor ao gado Curraleiro da comunidade Kalunga. Archivos de Zootecnia, v.60, n.231, p.357-369, 2011. 
OLIVEIRA, A.F.G.F. Contributo para o estudo qualitativo de carnes secas e salgadas de ovinos e caprinos. Composição química e análise microbiológica. Efeito da espécie. 2011. 92 f. Dissertação (Mestre em Qualidade e Segurança Alimentar) - Escola Superior Agrária de Bragança, Bragança. 2011.

OLIVEIRA, J.M.L.B. Denominações de origem e indicação geográfica - protecção e impacto socioeconômico. 2010. 38 f. Dissertação (Pós-Graduação em Economia e Gestão de Propriedade Industrial) - Instituto Superior de Economia e Gestão - ISEG. Bragança. 2010.

PEREIRA, L.K. O processo de valorização de produtos alimentícios através das denominações de origem e qualidade: uma abordagem de gestão do conhecimento. 2011. 169 f. Dissertação (Mestre em Engenharia de Produção) - Universidade Federal de Santa Catarina. Florianópolis. 2011.

RODRIGUES, A.M. O selo ecológico na União Europeia. In: CONGRESSO BRASILEIRO E INTERNACIONAL DE ZOOTECNIA, 13., 2003, Uberaba. Anais... Uberaba-MG, 2003. p. $162-179$.

SILVA, P.S. Denominações de origem e indicações geográficas. In: Curso de PósGraduação em Propriedade Industrial, 8., 2008, Portugal, Anais... Portugal,

TEIXEIRA, A.J.C. 2009. Produção e comercialização integrada de produtos caprinos e ovinos com denominação de origem: uma experiência de Portugal. In: Simpósio Internacional Sobre Caprinos e Ovinos de Corte - Feira Nacional do Agronegócio da Caprino - Ovinocultura de Corte, 4., 2009, João Pessoa. Anais... João Pessoa, 9 p.

TIBÉRIO, M.L.; CRISTÓVÃO, A. 2001. Produtos tradicionais e desenvolvimento local: 0 caso da designação protegida Queijo Terrincho DOP. In: Congresso de Estudos Rurais Território, Sociedade e Política - Continuidades e Rupturas, 1., 2001, Portugal, Anais... Portugal, $23 \mathrm{p}$.

VELLOSO, C.Q. Indicação geográfica e desenvolvimento territorial sustentável: a atuação dos atores sociais nas dinâmicas de desenvolvimento territorial a partia da ligação do produto ao território. 2008. 168 f. Dissertação (Mestrado em Ciências Agrárias) - Universidade Federal de Santa Catarina, Florianópolis, 2008. 